\title{
Experimental investigation on PM2.5 particle emission during polishing of granite
}

\author{
Jules Kouam $^{1}$, Victor Songmene ${ }^{1^{*}}$, Ali Balhoul ${ }^{2}$ \\ ${ }^{1}$ École de Technologie Supérieure (ÉTS), Montréal, Canada; \\ *Corresponding Author: victor.songmene@etsmtl.ca \\ ${ }^{2}$ Institut de Recherche Robert-Sauvé en Santé et Sécurité du Travail (IRSST), Montréal, Canada
}

Received 7 August 2013; revised 7 September 2013; accepted 1 October 2013

Copyright @ 2013 Jules Kouam et al. This is an open access article distributed under the Creative Commons Attribution License, which permits unrestricted use, distribution, and reproduction in any medium, provided the original work is properly cited.

\begin{abstract}
Particle emission during manufacturing processes, whether chemical, physical or mechanical can represent a serious danger for environment and for occupational safety. Especially machining processes, particle emission could have an important impact on shop floor air quality and might jeopardise workers' health. It is therefore important to find ways of reducing the particle emission at the source of manufacturing processes. To do so, there is a need to know the size, the quantity and the distribution of particles produced by processes currently used in industry. In this study, investigations are done to compare the particle emission (PM2.5) when polishing two granites (black and white). The black granite contained low Si concentration (about $10 \% \mathrm{Si}$ ) and the white granite contained high Si concentration (about $50 \%$ Si). Particle emission was monitored using the DustTrak II equipment with $2.5 \mu \mathrm{m}$ impactor. The particle grain size was evaluated using $X$-ray diffraction techniques. Machining conditions leading to the generation of finer particles were identified.
\end{abstract}

Keywords: Granite; Polishing; PM2.5; Particle Emission; Air Pollution

\section{INTRODUCTION}

Granite is worldwide appreciated and used as kitchen countertops, for decoration, memorials, landscaping and urban development, interior and exteriors building.

Most of these applications are due to the granite high wear resistance and good dimensional stability. These materials often need to be shaped and polished. Common machining operations usually used for granite include quarrying, saw milling, cutting, polishing and drilling. Xie et al. 2007 [1] and Xie, 2010 [2] have shown that the efficiency in grinding and drilling processes of the abrasive depends on the type of granite.

Each of granite extracting and shaping operation is susceptible of generating fine and ultrafine particles.

In fact, Ahmad et al. (2011) [3] studied the nanotoxicity of occupational dust generated in granite Saw Mill and found that this manufacturing process generates both micrometric and nanometric sizes particle. Their investigations also show that granite nanoparticles are signifycantly more toxic than microparticles. For that reason, the authors recommended that different safety standards be set for micro- and nano-size granite particles for better protection of occupational safety.

Some occupational silicosis have been reported for people involved in granite manufacturing [4,5]. Lung problems including cancer and kidney malfunction have also been reported [6].

In general, the potential risks associated with exposition to ultrafine particles is well documented [7-9]. Pozzi et al. 2003 [7] have shown that the simple inhalation of the urban air ultrafine particles (PM2.5) could pose a serious threat to human health. These particles are more harmful if they can penetrate the respiratory tract area, Chung 1996 [8].

Huang et al. 2002 [10] have shown in their work that when grinding granite, the chip removal mechanism varies from brittle mode to ductile mode depending for the diamond grit size and that the surface roughness decrease when increasing the grit size. However, the authors did not address the particle emission.

Yilmaz et al. [11] studied the particle size distribution and shape characterization of the chips produced during granite machining. They found that sharp tool produced larger-sized particle distribution than dull tool.

Many researchers have studied particle emission when machining metallic materials (Sutherland et al. 2000 [12], 
Songmene et al. 2008 [13], Khettabi et al. 2010 [14] and Kouam et al. 2012 [15]).

To the authors' knowledge, very limited works have been done on particle emission during granite machining. Thus, the results of the present study will be an important resource in this field. As were noticing Ahmad et al. (2011) [3], while studying the nanotoxicity of occupational dust generated in granite Saw Mill, the risk of occupational exposure to particles of granite exists when shaping it. They also found that these particles have predominantly micrometric and nanometric sizes, the potentially more dangerous. In order to help set new regulations, to reduce the dust emission at the source or to seek for appropriate protective methods, there is a need to understand the particle emission (quantity, shape, distribution, composition, etc.) when shaping the granite

The main objective of this study of this work is to examine the influence of machining conditions on particle emission during dry polishing of black and white granites.

\section{EXPERIMENTAL PROCEDURE}

Dry Polishing tests were carried out on two granites (black and white) using the device presented in Figure 1. The following polishing conditions and parameters were used:

- Cutting speeds: 880, 670 and $450 \mathrm{~m} / \mathrm{min}$

- Load : $2.5 \mathrm{~kg}$

- Abrasive grit : 60

- Polishing time : 1 min

- Lubrication: none

The particle emission was measured using TSI Dust Trak Aerosol Monitor instrument (Model 8530) in which a $2.5 \mu \mathrm{m}$ diameter impactor was mounted. The sampling pump flow rate was set at $1.5 \mathrm{l} / \mathrm{min}$.

$\mathrm{X}$-ray diffraction diagrams were obtained using an

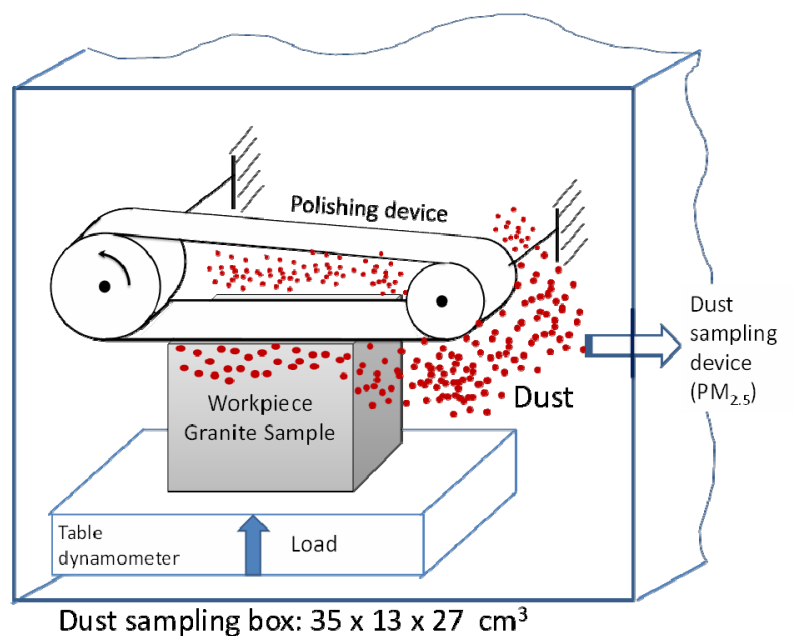

Figure 1. Experimental setup.
XRD diffractometer (PANalyticalX'Pert Pro Materials Research Diffractometer) with $\mathrm{CuK}_{\alpha 1}\left(\lambda_{\mathrm{K} \alpha 1}=1.5406 \AA\right)$ and $\mathrm{CuK}_{\alpha 2}\left(\lambda_{\mathrm{k} \alpha 2}=1.5444 \AA\right)$, which was used to evaluate the grain size of the particle obtained during dry machining under different cutting conditions.

The cutting forces were measured using a three-axis dynamometer (Kistler 9255B) and the surface finish of the polished samples was measured using the Mitutoyo S-J400 equipment. Each measurement of surface finish was done four times and the average value of the four measurements analyzed.

Figure 2 presents optical microscopy image of white granite and black granite. EDX (Electron Diffraction X) was also used for evaluating the material chemical composition at different zones as presented in Table 1.

\section{RESULTS AND DISCUSSIONS}

\subsection{Particle Emission}

Figure 3 presents the typical particles emission recorded when polishing white granite and black granites using a 60 grit abrasive and under a $2.5 \mathrm{~kg}$ load. It is observed that in general, low speed leads to lower particle generation and that at this low speed, white granite generates fewer mass particles concentration compared to black granite. White granite contents high Si concentration as it has been observed in Table $\mathbf{1}$ compared to black granite. This high Si concentration could increase the friction coefficient in white granite compared to black granite. It is also observed that when decreasing the cutting speed the particle mass concentration decreases for both materials. When decreasing the cutting speed during polishing there is a reduction of friction between the abrasive and the material.

Figure 4 presents the collected particles morphology images obtained from Scanning Electronic Microscopy (SEM). It is observed that at $880 \mathrm{~m} / \mathrm{min}$ cutting speed particles generated from white granite are more agglomerated than those obtained on black granite. As it has been observed in Figure 3, white granite generates fewer particles compared to black granite and this process could be the origin of the agglomeration. It is also observed that when decreasing the cutting speed the level agglomeration decreases for both materials. Decreasing the cutting speed during polishing leads to the a reduction of particles speed displacement which could reduce the agglomeration effect

Figure 5 and Figure 6 present the average and the total mass concentration of particles emitted. The average and total of mass concentration obtained from Figure 3. Figure 5 and Figure 6 confirm the observations presented in Figure 3: the increase in polishing speed leads to higher generation of particle. The total mass has been obtained using Simpson formula. 


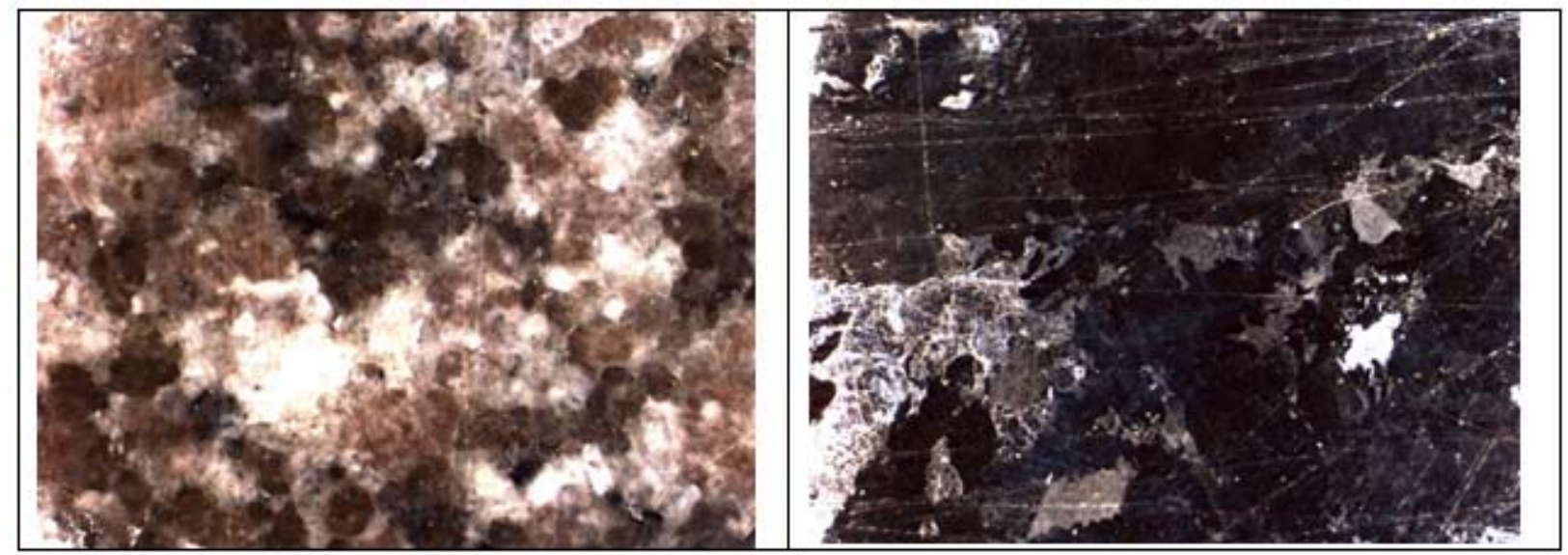

(a)

(b)

Figure 2. Optical microscopy images of workpiece materials: (a) white granite (b) black granite.

Table 1. Chemical composition from EDX of white and black granites.

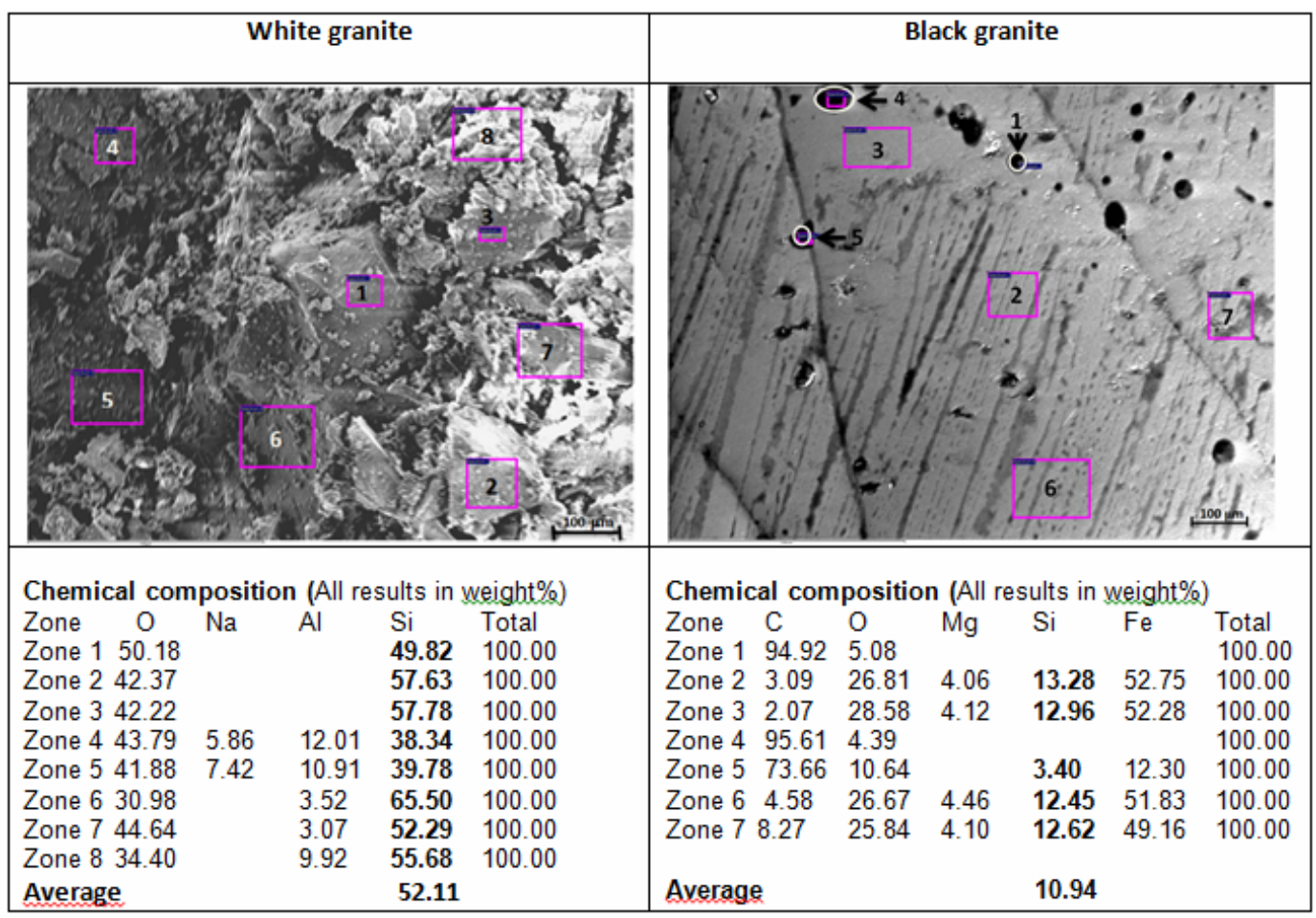

\subsection{X-rays Diffraction Analysis}

Figure 7 present the XRD diagrams of particles collected. These diagrams were analysed according to the deconvolution of the peak in two Lorentzians corresponding to the two components $\lambda_{\mathrm{K} \alpha 1}$ and $\lambda_{\mathrm{K} \alpha 2}$ of the wavelength $\lambda_{\mathrm{K} \alpha}$ of copper. This procedure yields a measurement of a width for each peak (FWHM), corresponding to a well-defined wavelength, and has been applied to the whole diagram. This procedure has been already developed by Kouam et al 2008 [16] and Kouam et al 2013 [17]. Several observations can be made:
- The positions of the diffraction peaks of the initial white granite are shifted slightly to the small $\theta$ angles as compared to those of the black granite. That is because of the Si content, which is high in the white granite compared to black granite.

- The diffraction peaks of the white granite are widened and more scattered as compared to those which are observed on the black granite.

Because the peak width depends on the crystallographic direction considered, the maximum intensity ratio differs slightly from theoretical computations. It is necessary to consider integrated intensities when com- 


\section{Cutting speed}

$(\mathrm{m} / \mathrm{min})$

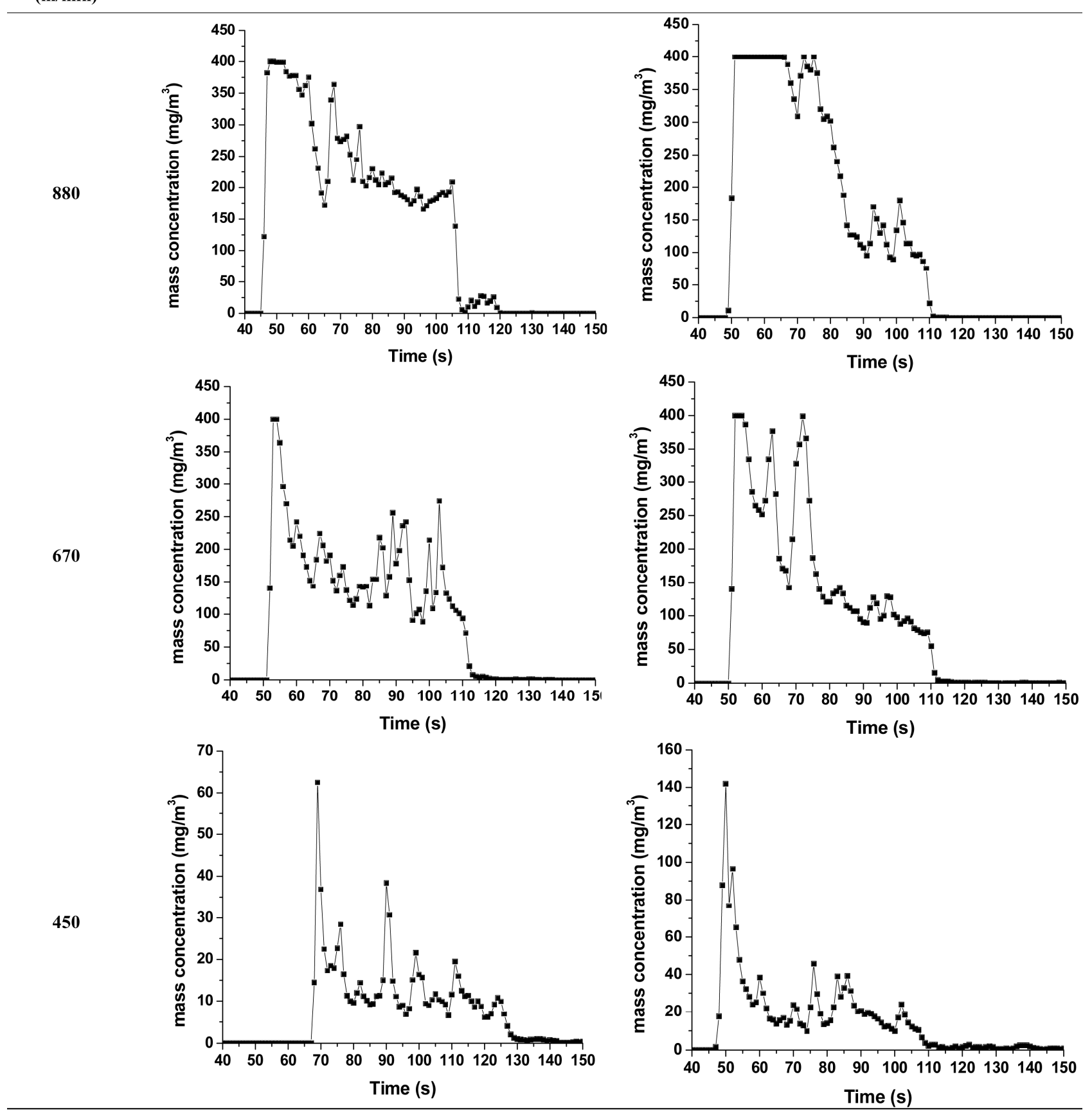

Figure 3. Particles emission at different cutting speed using 60 grit abrasive, $2.5 \mathrm{~kg}$ load.

paring real values to computed ones.

Figure 8 presents the particles grain size $d_{m}$ computed from XRD analysis. It is observed that for each material, the particle grain size $\mathrm{d}_{\mathrm{m}}$ decreases with the cutting speed. This observation confirms SEM image analysis (Figure 4). On the other hand, at the same cutting speed, the particle grain size $d_{m}$ is high when polishing white granite compared to black granite. This effect could be inter- preted as owing to crystallographic effects due to the high Si content in white granite.

\subsection{Part Finish Surface}

Figure 9 presents the average roughness of polished parts. The roughness decreases when increasing the cutting speed for both materials. This observation confirms that the surface finish improves as the cutting speed in- 


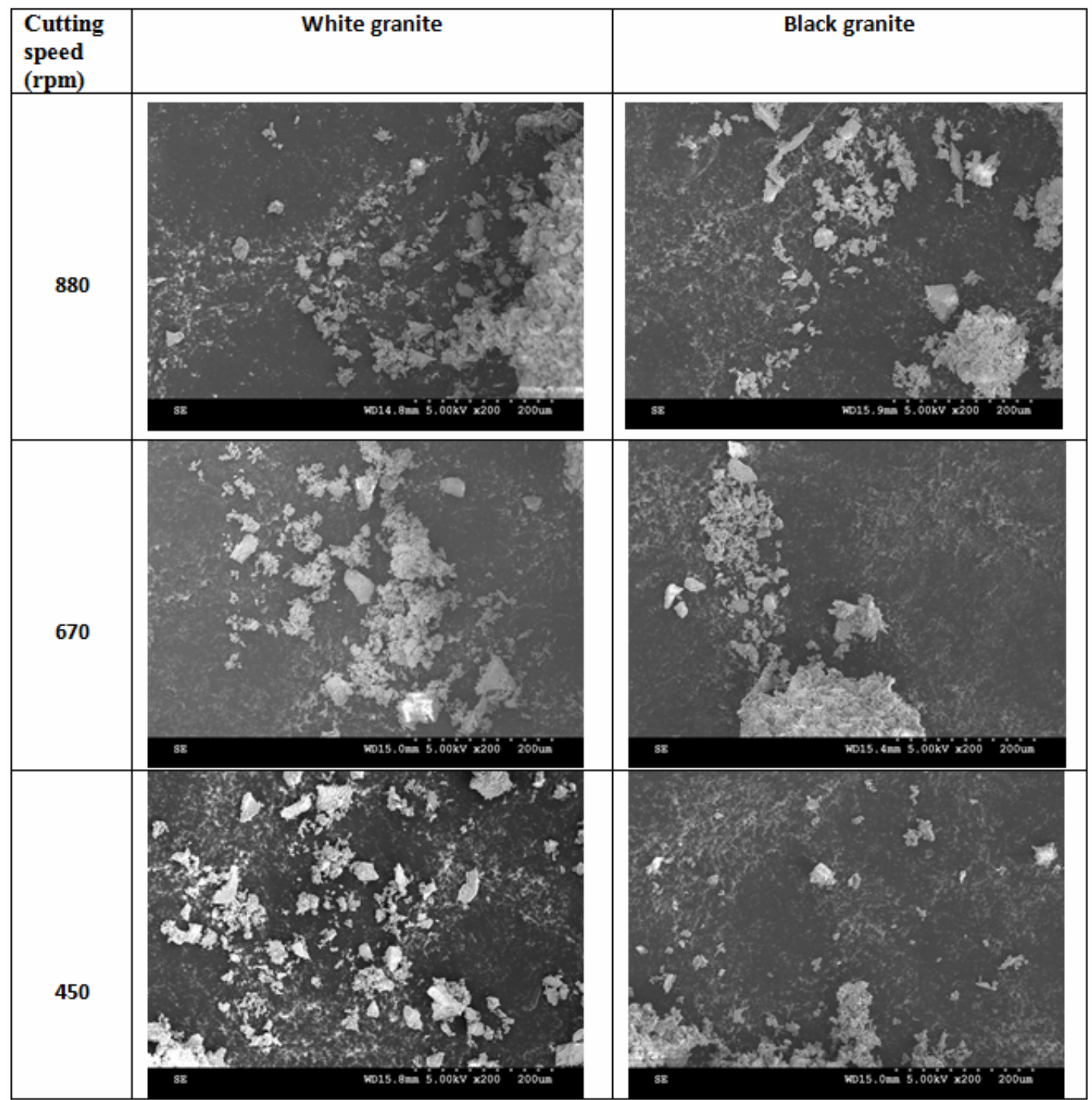

Figure 4. SEM images of particles morphology.

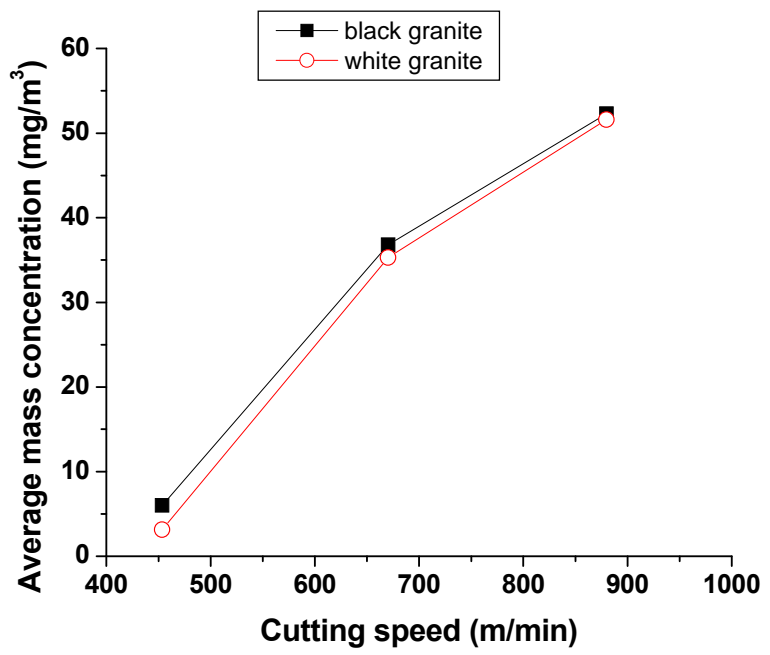

Figure 5. Average of mass concentration of Particles emission at different cutting using 60 grit abrasive and $2.5 \mathrm{~kg}$ load.

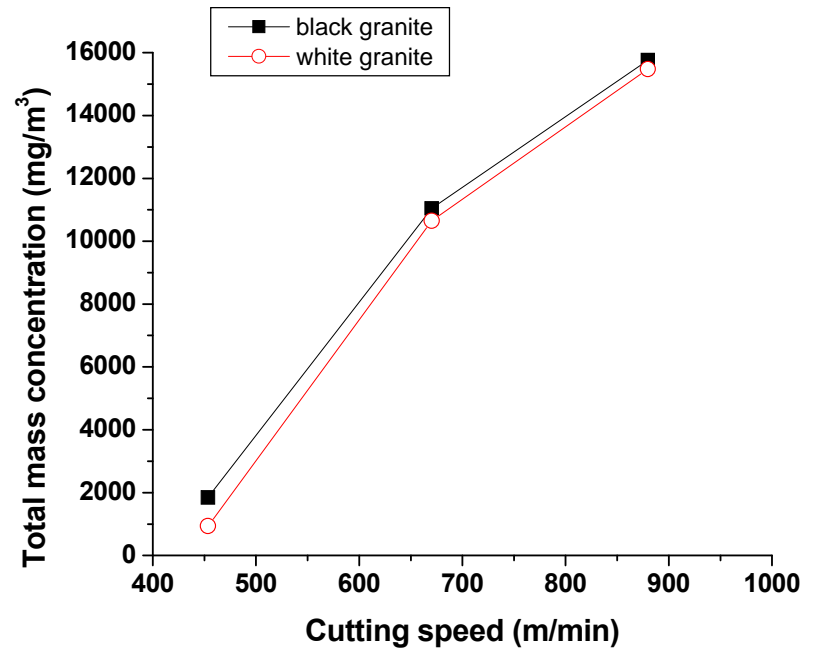

Figure 6. Total of mass concentration of Particles emission at different cutting using 60 grit abrasive and $2.5 \mathrm{~kg}$ load. 


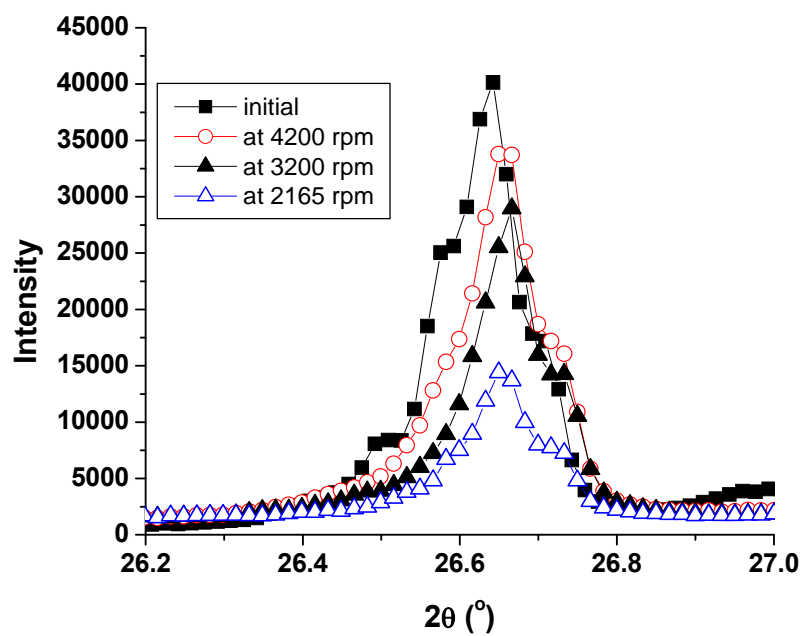

(a)

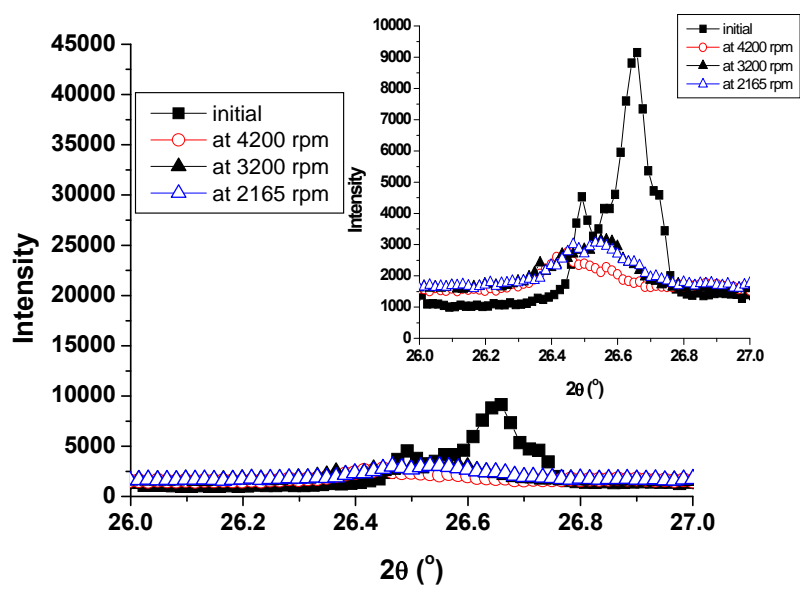

(b)

Figure 7. XRD diagram at different cutting speed of white and black granite. (a): White granite; (b): Black granite.

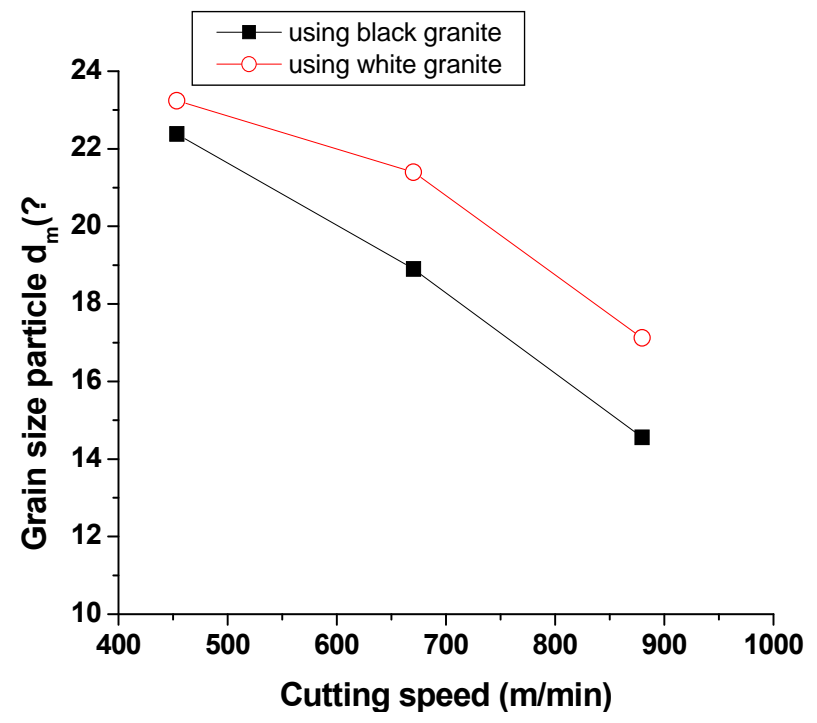

Figure 8. Particle grain size at different cutting speed of white and black granite.

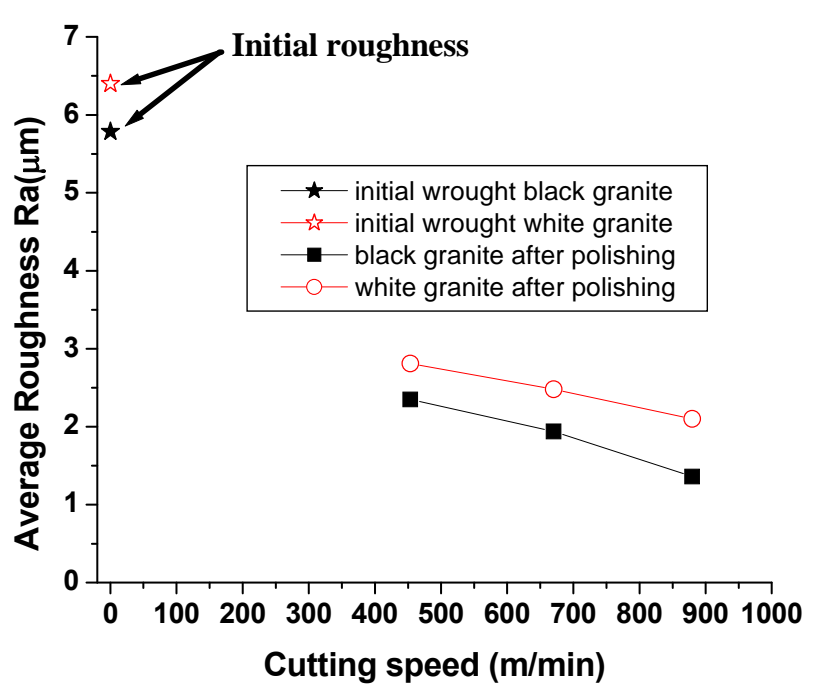

Figure 9. Average roughness, Ra, at different cutting speeds of white and black granite.

creases, and is itself confirmed by the work of Fu et al. 2010 [18] in milling tests and by the work done by Kouam et al. 2012 [15] in the friction tests in which the tool was in rotation and displacement (similar to polishing process).

It is also observed that the roughness of white granite is high compared to black granite. This can be related to the high Si content of white granite compared to black granite (Table 1). This high Si concentration could increase the friction coefficient in white granite compared to black granite. This high friction coefficient in white granite could explain its high roughness compared to black granite

\section{CONCLUSION}

In this work, the effect of machining condition when polishing white and black granite was studied. It was found that during this process, the surface roughness and the particle emission depend significantly on quartz content in granite and on cutting conditions.

- Particle emissions were found to be affected not only by the cutting condition but also by the Si content. Black granite (low Si content) generates more particles than white granite (high Si content). This observation could help reduce dust emissions, which can have serious consequences on the health of the operator.

- Using high cutting speed leads to the generation of finer particles and better polished surface compared to those obtained at low speed.

- From the XRD analysis, the change in particle grain size with the cutting conditions confirmed the change on particle microstructure during the dry polishing process. 


\section{ACKNOWLEDGEMENTS}

This research work is part of a large project on granite funded by the Institut de Recherche Robert-Sauvé en Santé et Sécurité du Travail (IRSST). The authors also acknowledge Kevin Lauzon for his assistance during experimental testing and Lacroix granit industry for samples donation.

\section{REFERENCES}

[1] Xie, J. and Tamaki, J. (2007) Parameterization of microhardness distribution in granite related to abrasive machining performance. Journal of Materials Processing Technology, 186, 253-258. http://dx.doi.org/10.1016/j.jmatprotec.2006.12.041

[2] Xie, J. (2010) Precision grindability of granite in Relation to Discrete Distribution Parameters of Microhardness and Microbrittleness, Journal of Manufacturing Science and Engineering, 132, 1-7. http://dx.doi.org/10.1115/1.4001578

[3] Ahmad, I., Khan, M.I. and Patil, G. (2011) Nanotoxicity of occupational dust generated in granite stone saw mill. International Conference on Nanoscience, Technology and Societal Implications, Bhubaneswar, 8-10 December 2011, 1-6. http://dx.doi.org/10.1109/NSTSI.2011.6111990

[4] Graham, W.G. Costello J. and Vacek, P.M. (2004) Vermont granite mortality study: An update with an emphasis on lung cancer. Journal of Occupational and Environmental Medicine, 46, 459-466.

http://dx.doi.org/10.1097/01.jom.0000126026.22470.6d

[5] Kulkarni, G.K. (2007) Prevention and control of silicosis: A national challenge. Indian Journal of Occupational and Environmental Medicine, 11, 2007, 95-96.

http://dx.doi.org/10.4103/0019-5278.38456

[6] P. Jayawardana, Tennakoon, S. and Bandara, V. (2008) Respiratory symptoms and ventilatory function among granite workers working in quarries installed with mechanical crushers in and around Kandy Municipality limits. Journal of the College of Community Physicians of Sri Lanka, 13, 9-16.

[7] Pozzi, R., De Barardis, B., Paoletti, L. and Guastadisegni, C. (2003) Inflammatory mediators induced by coarse (PM2.5-10) and fine (PM2.5) urban air particles in RAW 264.7 cells. Toxicology, 183, 143-254. http://dx.doi.org/10.1016/S0300-483X(02)00545-0

[8] Chung, A. (1996) The uptake of mineral particles by pulmonary epithelial cells. American Journal of Respiratory and Critical Care Medicine, 154, 1124-1140. http://dx.doi.org/10.1164/ajrccm.154.4.8887617
[9] Seaton, A., MacNee, W., Godden, D. and Donaldson, K. (1995) Particulate air pollution and acute health effects. Lancet, 345, 176-178. http://dx.doi.org/10.1016/S0140-6736(95)90173-6

[10] Huang, H., Li, Y., Chen, J.Y., Zhu, H.M. and Xu, X.P. (2002) Micro-structure detection of a glossy granite surface machined by grinding process. Journal of Materials Processing Technology, 129, 403-407. http://dx.doi.org/10.1016/S0924-0136(02)00702-1

[11] Yilmaz, N.G., Goktan, R.M., Gasan, H. and Celik, O.N. (2013) Particle size distribution and shape characterization of the chips produced during granite machining in relation to process forces and specific energy. Particulate Science and Technology, 31, 277-286. http://dx.doi.org/10.1080/02726351.2012.726943

[12] Sutherland, J.W., Kulur, V.N. and King, N.C. (2000) Experimental investigation of air quality in wet and dry turning. CIRP Annals-Manufacturing Technology, 49, 61-64.

[13] Songmene, V., Balout, B. and Masounave, J. (2008) Clean machining: Experimental investigation on dust formation: Part I and part II. International Journal of Environment Conscious Machining (ECDM), 14, 1-33.

[14] Khettabi, R., Songmene, V., Zaghbani, I. and Jacques Masounave, J. (2010) Modeling of particle emission during dry orthogonal cutting. Journal of Materials Engineering and Performance, 19, 776-789. http://dx.doi.org/10.1007/s11665-009-9538-z

[15] Kouam, J., Songmene, V., Djebara, A. and Khettabi, R. (2012) Effect of friction testing of metals on particle emission, Journal of Materials Engineering and Performance, 21, 965-972.

[16] Kouam, J., Ait-Ahcene, T., Plaiasu, A.G., Abrudeanu, M., Motoc, A., Beche, E. and Monty, C. (2008) Characterization and properties of $\mathrm{ZnO}$ based nanopowders prepared by solar physical vapor deposition (SPVD). Journal of Solar Energy, 82, 226-238. http://dx.doi.org/10.1016/j.solener.2007.07.008

[17] Kouam, J., Songmene, V., Zedan, Y., Djebara, A. and Khettabi, R. (2013) On chip formation during drilling of cast aluminum alloys. Journal of Machining Science and Technology, 17, 228-245. http://dx.doi.org/10.1080/10910344.2013.780546

[18] Fu, X., Pan, Y., Wan, Y. and Ai, X. (2010) Research on predictive model surface roughness in high speed milling for aluminum alloy 7050-T7451. Proceedings of 2010 International Conference on Computing, Control and Industrial Engineering, 186-189. 